\title{
AS CANTIGAS DE CAPOEIRA ANGOLA: LITERATURA ORAL E TRADIÇÃO POPULAR
}

Carla Alves de Carvalho Yahn. Mestranda na Faculdade de Ciências e Letras/ Júlio de Mesquia Filho Universidade Estadual Paulista.

Prof. Dr. Rubens Pereira dos Santos. Departamento de Literatura - Faculdade de Ciências e Letras/ Júlio de Mesquia Filho - Universidade Estadual Paulista - UNESP

\begin{abstract}
RESUMO: Pretende-se olhar as cantigas de Capoeira Angola como forma da tradição oral afro-brasileira e, conseguintemente, como parte da Literatura Popular que resiste em nossa terra por meio de manifestações culturais, como é o caso da Capoeira Angola, que apresenta principalmente em suas ladainhas, temas diversos como o que se refere ao cotidiano do capoeirista, ao mito, e ao sublime. Algumas figuras como Riachão, Pedro Cem, Besouro de Mangangá, Valente Vilela, entre outras que aparecem nas cantigas de Capoeira Angola podem ser também encontradas na Literatura de Cordel, em seus contos rimados e em seus versos cantados.
\end{abstract}

PALAVRAS-ChAVE: Literatura Popular, Capoeira Angola, Cantigas.

ABSTRACT: It is looking at the songs of Capoeira Angola as a form of oral tradition african-brazilian, and therefore as part of Literature Popular who stand in our land through cultural events, such as Capoeira Angola, which has mainly in his litany, different subjects as far as the daily life of poultry, the myth, and the sublime. Some figures as Riachão, Pedro Cem, Besouro de Mangangá, Valente Vilela, and others that appear in songs of Capoeira Angola can also be found in the literature of Cordel in their rhymed narratives and their sung verses.

KEYWORDS: Literature Popular, Capoeira Angola, dittys.

\section{Introdução}

A Capoeira Angola é uma arte que abrange a dança, o teatro, a música, a literatura e a luta. As correntes que discutem sua origem são contraditórias e incertas. As mais significativas são as que defendem que a Capoeira se originou na África, mais propriamente no sul de Angola, com negros denominados bantu, esses negros tinham um ritual chamado de $N^{\prime}$ golo, que traduzindo significa "dança da zebra", era um ritual ancestral onde dois guerreiros lutavam e o vencedor poderia escolher sua noiva entre as meninas iniciadas na vida adulta. Há também as correntes que acreditam que a Capoeira é genuinamente brasileira, tendo se originado nos quilombos por conta da situação em que os escravos se 
encontravam, ou seja, longe de sua terra, sendo dominados e escravizados. Assim o negro sentiu a necessidade de criar técnicas de defesa pessoal, e, dessa forma, criou uma luta camuflada na dança e na música. Mas isso tudo não é nada simples, aqui se expõe essas idéias de forma bastante reducionista pelo fato desse artigo ser mais de caráter lingüístico-literário do que histórico.

Como o presente trabalho busca adentrar o universo de uma manifestação cultural de caráter popular, que possui como fundamento principal a música e a tradição oral, as quais possibilitam a expressão de suas cantigas, se deve antes de tudo explorar um pouco essa parte que é um tanto rica e fascinante e relacioná-la com o universo da arte poética, que também tem por fundamento algumas características comuns à música, e, por conseqüência às cantigas de Capoeira Angola, como é o caso da rima, do ritmo, da entoação, do tom e da cadência.

A Capoeira Angola possui léxico próprio e sua linguagem não é somente verbal, sendo também de expressão corporal e musical, assim, ela não deve ser reduzida à luta (arte marcial), mesmo com sua grande eficiência como tal, ela também não deve ser reduzida à dança folclórica e muito menos a teatro de rua, pois, antes de tudo, ela funciona desde seu surgimento no Brasil como manifestação cultural de raiz africana que busca a liberdade antes de tudo, é no espaço da roda de Capoeira que os escravos podiam transcender mediante a realidade em que se encontravam no tempo de cativeiro.

\section{A Musicalidade}

Há na Capoeira Angola oito instrumentos musicais que compõem a bateria, são eles: três berimbaus (gunga, médio e viola) instrumentos de corda única, compostos por uma verga de madeira, por um arame, por uma cabaça (planta de vegetação rasteira que serve como caixa de ressonância) e por um dobrão (moeda grande), cada um desses três berimbaus tem sua função sonora e prática específica, o primeiro de timbre grave comanda a roda, geralmente é tocado por um mestre mais velho e detentor de mais conhecimento, o segundo possui timbre intermediário, e sua função também é de intermediar entre gunga e viola, e o terceiro é de timbre mais agudo, sua função é repicar; dois pandeiros, antiqüíssimo instrumento musical da velha Índia; um reco-reco ou ganzá, instrumento de origem supostamente indígena, geralmente é feito de bambu; um agogô, palavra de origem nagô, que traduzida significa sino, é um instrumento musical feito de ferro ou 
castanha do Pará; e um tambor (atabaque), de paradeiros semelhantes aos do pandeiro. Ambos os vocábulos, pandeiro e atabaque, estão presentes na Literatura de Gil Vicente e no Cancioneiro da Ajuda.

Segundo os mestres mais antigos e mais tradicionais a bateria é o coração da roda de Capoeira Angola, é ela que dá o ritmo, que comanda e que arrepia, que aflora os muitos sentimentos dos que estão presentes e que inspira os mais sublimes versos de ladainhas, corridos e louvações. Alfredo Bosi diz algo semelhante a respeito da oralidade musicada: "é no coração da música oral que se formam as constantes do verso" (BOSI, 1977, 85)

\section{A Cantiga}

Segundo André Luis Lopes, no seu texto A capoeira na literatura de Cordel, dentro das cantigas de Capoeira:

Existe a cantoria sobre temas históricos, românticos, de valentia, religiosos, reivindicatórios e tantos outros. Temos, portanto, um prato cheio que ainda não foi servido nas mesas de discussão. Algumas dezenas, talvez centenas de Festivais de Cantos de Capoeira já foram realizados, mas nenhum deles com a preocupação de refletir e fazer refletir sobre as funções da cantoria na Capoeira. (LOPES, 2006, p. 1)

É importante frisar-se desde início que muitas cantigas de domínio público cantadas em rodas de Capoeira Angola também podem ser cantadas em manifestações culturais como o Jongo, o Coco Pernambucano e o Samba de Roda, tanto carioca como o do Recôncavo Baiano, dentre outras manifestações artísticas.

A maior parte dessas cantigas é cantada em língua portuguesa, o que, ao lado da navalha e do pandeiro, demonstra o quanto a influência portuguesa também está presente nessa arte. Há algumas cantigas expressas em língua Yoruba, o que revela a resistência Africana no que se refere à questão lingüística.

Os três cânticos expressos na roda de Capoeira Angola são as ladainhas ou hinos, as louvações ou chulas e os corridos. A ladainha geralmente é mais longa que os ouros cânticos, ela pode ter diversas funções, pode ser um apelo, uma vocação, uma sátira, tratar de temas de amor ou heróicos, pode ser uma narrativa histórica, uma denúncia social, um agradecimento e muito mais. A louvação é um momento de exaltação, nela pode-se exaltar Deus, uma determinada terra, uma determinada pessoa, uma ação, alguns instrumentos como a faca de ponta, por exemplo. Os corridos é o sinal verde para o jogo da Capoeira, quando eles são 
cantados os capoeiristas podem "vadiar", são cânticos que assim como a ladainha tratam de temas diversos, podem ser de domínio público, espontâneos e improvisados ou anteriormente elaborados e trabalhados. Dentro de tudo isso, pode-se encontrar vários tipos de cantigas, como as de mal dizer e escárnio, as de amor, as de devoção, as agiológicas (que se referem com detalhes a santos católicos ou personagens bíblicas), as de sotaque e desafio, as geográficas e de louvação. À caráter demonstrativo e de análise literária segue abaixo uma ladainha de Capoeira Angola e, em seguida um poema de Mário de Andrade:

Vou-me embora vou-me embora

Vou-me embora pra Bahia

Vou jogar a capoeira

Essa é minha garantia

Vou-me embora dessa terra

Vou ver se dinheiro faço

Se dinheiro não fizer

Tento desatar o laço

Vou-me embora vou-me embora

Como já disse que vou

Se não for nessa semana

$\mathrm{Na}$ outra que vem eu vou

Vou-me embora vou-me embora

Eu não posso demorar

Vou levar flor de laranjeira

Pro meu benzinho cheirar

(cantiga de domínio público)

$$
\text { *** }
$$

Vou-me embora vou-me embora

Vou-me embora pra Belém

Vou colher cravos e rosas

Volto a semana que vem

Vou-me embora paz da terra

Paz da terra repartida

Uns tem terra muita terra

Outros nem pra uma dormida

Não tenho onde cair morto

Fiz gorar a inteligência

Vou reentrar no meu povo

Reprincipiar minha ciência

Vou-me embora vou-me embora Volto a semana que vem Quando eu voltar minha terra Será dela ou de ninguém 
Com os exemplos citados acima fica bem clara a semelhança que existe entre o poema de Mário de Andrade, que se encontra na obra $O$ carro de miséria, com a ladainha de domínio público cantada geralmente em rodas de Capoeira Angola. Ambos apresentam métrica semelhante, com versos em redondilhas dispostas em quadras; os dois textos apresentam grandes traços da oralidade, como o mote "vou-me embora", característica de uma Literatura predominantemente popular, que possibilita a memorização de seus versos; as rimas que valorizam uma sonoridade que auxilia no cantar do poema; o ritmo cadenciado pelo fluxo das idéias que são narradas em primeira pessoa; ambos apresentam uma estilização culta da linguagem popular: "reentrar", "reprincipiar", "desatar", o que comprova que a linguagem popular não é somente baseada no dizer cotidiano, mas possui suas especificidades e belezas, que muitas vezes, como não é o caso do exemplo proposto, porém acontece em muitos outros textos, fazem florir neologismos espetaculares que deixam transparecer uma boa pitada de criatividade e sentido.

Voltando aos poemas orais escolhidos, pode-se notar que ambos tratam de temas condizentes: a falta de dinheiro, a posição social desprivilegiada e a busca por uma melhora de vida. Como já é sabido, Mário de Andrade desenvolveu, nesse poema, um tema que está presente em boa parte de sua obra, a crítica social a partir da valorização da arte popular, dando-lhe um caráter erudito e literário. Nos dois textos tem-se presente a questão do homem pobre que não possui dinheiro e, muito menos terra. Aqui o eu poético vê na migração uma solução para seu problema, o primeiro vai para a Bahia, o segundo para Belém. Essa atitude, ainda em dias atuais, é comum entre muitos brasileiros que buscam uma melhora na situação econômica em que vivem. Mesmo com essa característica temática, não se pode deixar de destacar como mesmo com a dureza desse tema ainda flori a delicadeza romântica que aparece nos versos "vou levar flor de laranjeira/pro meu benzinho cheirar" do primeiro poema e no verso "vou colher cravos e rosas" do segundo.

É bom salientar-se que Mário de Andrade fez uma assídua pesquisa das manifestações culturais de cunho popular no Brasil. Ele trouxe para sua obra boas contribuições dessa pesquisa, transformou em erudito o popular, e demonstrou o quanto é rica e significante a tradição oral, que desde os primórdios foi a base da 
Literatura, como a Ilíada e a Odisséia, como muitos livros bíblicos, e que hoje continua sendo um alicerce que sustenta boa parte da Literatura, e que, ainda em tempos tão esclarecidos, é tida por uma elite conservadora como algo sem prestigio literário, uma literatura inferior, e não é considerada a "Verdadeira Literatura". Mário de Andrade, ao contrário, tentou resgatar a inteligência brasileira, preservar e valorizar seu patrimônio artístico, literário e cultural, o que fica bastante evidente no poema exposto anteriormente.

\section{3- O Ritmo}

A relação entre ritmo e palavra poética não é diferente da relação que reina entre a dança e o ritmo musical: não se pode dizer que o ritmo é a representação sonora da dança; nem tampouco que o bailado seja a tradução corporal do ritmo. Todos os bailados são ritmos; todos os ritmos, bailados. No ritmo já está a dança e vice-versa. (PAZ, 1982, P. 70)

Segundo autor citado acima o ritmo é um ir em direção a algum lugar, ou a alguém. É um processo, é continuo, é a vida, é o tempo real, é um caminhar que pode ter intensidades diversas. O ritmo ao lado da musicalidade é elemento fundamental na Capoeira assim como o é na Literatura, é ele que rege e é regido pela dança, pelos versos, pela música, pois é inseparável desses domínios: “Os ritmos poéticos nascem na linguagem do corpo, na dança dos sons, nas modulações da fala" (BOSI, 1977, 85)

\section{4- A Memória e o Mito}

“O poema se nutre da linguagem viva de uma comunidade, de seus mitos, seus sonhos e suas paixões, isto é, suas tendências mais secretas e poderosas" (PAZ, 1982, p. 49)

As ladainhas, as chulas e os corridos transmitem muito da memória oral e histórica da capoeira que é passada no ritual da roda de geração para geração, sofrendo algumas alterações, mas mantendo grande parte do sentido original. Além das cantigas existem também os mitos heróicos de capoeiristas de todos os tempos que são expressos não só através delas, mas através também da linguagem do povo. Um dos mais significativos e lendários é o mito do Besouro Mangangá, conhecido também como Besourinho de Santo Amaro, Besouro Preto, e o muito cantado na capoeira Besouro Cordão de Ouro. Muito pouco se sabe sobre essa figura mística, há pouco tempo estudiosos descobriram seu registro de nascimento. De antemão pode-se admitir sua 
importância popular que permanece até hoje no imaginário de muitas comunidades nacionais. Mestre Moraes, relata no documentário Besouro Preto de Salim Rollins, que desconfia das lendas de Besouro, ele afirma que os homens têm limites, podem fazer coisas excepcionais, mas não se transformar num Besouro e desaparecer.

Besouro foi um valentão capoeirista que todos temiam. Era o pai dos injustiçados e o terror da polícia e da elite. Aparece dentro das rodas de capoeira como homem místico de corpo fechado. Era mágico, fazia soldado voltar bêbado para o quartel, dava rabo-dearraia numa tropa inteira e depois desaparecia, diz a lenda que ele se transformava em um Besouro e saia voando. Era o mais mandingueiro, tinha proteção espiritual. Tinha cravado na sua pele a fava da índia, de encanto que só poderia ser quebrado por três elementos: a faca de ticum (árvore encontrada no Brasil), a briga depois de ter deitado com mulher e ter passado debaixo de arame farpado. Numa ocasião Besouro bate no filho de uma autoridade e é tido por morto. Segundo a lenda, no dia de sua morte Besouro deitou-se com uma de suas raparigas, que havia sido paga por essa autoridade para tirar seu patuá, passou por debaixo de arame farpado e brigou com policiais, sendo que um deles se encontrava com a faca de ticum para feri-lo. Besouro viaja muito tempo de canoa à procura de socorro. Depois de socorrido Besouro recebe a notícia de que não seria mais o mesmo. Então Besouro se recusa a viver e morre. A cantiga a seguir fala de Besouro:

\author{
Besôro stava dormindo \\ Acordô todo assustado \\ Deu um tiro in baraúna \\ Pensando qui era sordado. (REGO, p. 123,124)
}

A quadra acima é bastante simples e seu esquema de rima é a/b/c/a, o poema é composto por versos em redondilha maior, e preza muito a musicalidade dos mesmos, trocando as preposições em e que porin e qui, o que contribui ao som da cantiga que geralmente é cantada em ritmo acelerado. Ainda a caráter analítico e comparativo, segue abaixo um breve trecho de literatura de cordel que trata do personagem lendário Besouro Preto:

Nas rodas de capoeira

Seu nome é muito cantado

Fora das rodas também

Ele é sempre lembrado

Como um grande capoeira

Que tinha o corpo fechado 
As sextilhas acima revelam a importância da figura de Besouro nas rodas de capoeira, e, como seu nome não se limita dentro desta manifestação cultural, pois o imaginário popular já tem em si grandes e diversas versões a respeito deste mito. Relembra seus três nomes, que é chamado conforme a região, e sua valentia e coragem, sua virtude de ser capoeirista e sua força descomunal que provavelmente se originara de seu misticismo, pois tinha o corpo fechado.

Quanto à forma, o trecho do poema ou do conto rimado, como prefere definir alguns críticos, é, assim como o trecho da cantiga anteriormente analisada, formado por versos em redondilha maior, o que privilegia a oralidade da obra. Seu esquema de rima é $\mathrm{a} / \mathrm{b} / \mathrm{c} / \mathrm{b} / \mathrm{a} / \mathrm{b}$ na primeira sextilha, e d/e/f/e/h/e na segunda. Seu ritmo é bastante cadenciado e desemboca na própria figura de Besouro.

Há também outras figuras lendárias dentro da capoeira, como o mito de Riachão, Pastinha, Cobrinha Verde, Zumbi, Pedro Cem, Valente Vilela, dentre muitos outros grandes capoeiristas místicos do Brasil.

\section{Conclusão}

Por mais que pareça ser impossível, é possível sim estudar as relações que existem entre as cantigas populares de Capoeira Angola com a Literatura, independente de seu adjetivo, seja ele popular, erudita, marginal, oral. Além de ser revolucionário, esse trabalho tenta quebrar alguns preconceitos que ainda existem em relação à determinadas criações populares que incontestavelmente deixa revelar seu caráter literário e válido para grupos diversos de leitores. Já foi provado, como acontece na obra de Márcia Abreu, Cultura letrada: Literatura e leitura, que muitos leitores se deixam influenciar pelo gosto canônico, de uma elite social que dita o que deve e o que não deve ser considerado como Literatura. Esse trabalho tenta resgatar a noção de inteligência artística e criatividade textual de obras da tradição oral, de origem popular que podem deixar transparecer muito da literariedade que emana de seus versos e de seus contos rimados. 


\section{Referências bibliográficas:}

ABREU, Márcia. Cultura letrada: Literatura e leitura. São Paulo: Editora Unesp, 2006.

ANDRADE, Mário de. Lira Paulistana \& O carro da miséria. São Paulo: Martins, 1945.

BOSI, A. O ser e o tempo da poesia. São Paulo: Cultrix, 1977.

GARCIA, Victor Alvim. Histórias e bravuras de Besouro/ o valente capoeira. LOPES, André Luis Lace. "Capoeira na Literatura de Cordel”. Disponível em: Cordel. S/L, S/E, S/D.

http://www.jornalexpress.com.br/noticias/detalhes.php?

id jornal=13170\&id_noticia $=465$ acesso em 25 maio 2009 (2006) p. 01.

PAZ, Octavio. O arco e a lira. Rio de Janeiro: Nova Fronteira, 1982.

REGO, Waldeloir. Capoeira Angola - Ensaio Sócio-Etinografico. Bahia: Itapoá, 1968.

RESENDE, Garcia de. Miscelânea/ e variedade de histórias, costumes, casos, e cousas que em seu tempo aconteceram. França Amado - Editor, Coimbra, 1917.

SAMPAIO, Teodoro. O tupi na geografia nacional. 4ํㅡㄹ Ed. Câmara Municipal de Salvador, Salvador, 1955.

SOARES, Eugênio Líbano Soares. A capoeira escrava. 2a Ed. Campinas: Editora da Unicamp, 2002.

VASCONCELOS, Carolina Michaelis de. Cancioneiro da Ajuda/ edição crítica e comentada. Vol. II. Max Niemeyer: Halle, 1904.

VIEIRA, Luiz Renato. O jogo da capoeira: cultura popular no Brasil. Rio de Janeiro: Sprint, 1995. 